\title{
Course and Prognosis in Aplastic Anaemia
}

\author{
S. M. LEWIS, ${ }^{*}+$ M.D., B.SC., D.C.P., M.C.PATH.
}

Brit. med. F., 1965, 1, 1027-1031

The diagnosis of aplastic anaemia depends upon the demonstration of hypocellularity of the bone-marrow, and before making the diagnosis it is essential to demonstrate this by appropriate marrow aspiration, bone-biopsy, and special investigations: Even so, this diagnosis includes a number of entities which differ in behaviour and prognosis and are probably due to different fundamental defects. They include congenital and familial aplastic anaemias, bone-marrow injury due to ionizing radiation, and chronic acquired aplastic anaemia. In a number of instances of acquired aplastic anaemia there is an undoubted causal relation with a chemical substance, but often there is no apparent history of an aetiological agent and, conversely, it may not be possible to define the relation of the disease with a drug known to have been previously administered. It is therefore convenient to study the idiopathic and secondary groups together.

During the past 12 years 60 patients with chronic acquired aplastic anaemia have been investigated at the Postgraduate Medical School. On the basis of this experience problems of diagnosis are reviewed and influences which affect prognosis are analysed. The patients came from a wide area, including a few from overseas. Those referred for consultation tended to be the more serious cases, and the series cannot therefore be regarded as an unselected one.

\section{Clinical Findings}

Age and Sex.-Fig. 1 shows the age distribution in the series. The youngest patient was 2 years old and the oldest was 80 . There has been no significant preponderance of either sex in the series as a whole or in any age-group, except for a (presumably chance) finding that all the patients between the ages of 35 and 40 were women.

* Lecturer in Haematology, Postgraduate Medical School, London. + In receipt of a grant from Smith Kline and French Foundation.
Aetiological Factors.-A definite history of exposure within the previous six months to a "toxic" agent known or thought to have caused marrow aplasia was obtained in 28 patients (Fig. 1). In some cases more than one drug had been administered and it was not, as a rule, possible to be certain which (if any) of the incriminated substances was responsible. They are listed in Table I. In the remaining 32 patients no aetiological factor could be determined.

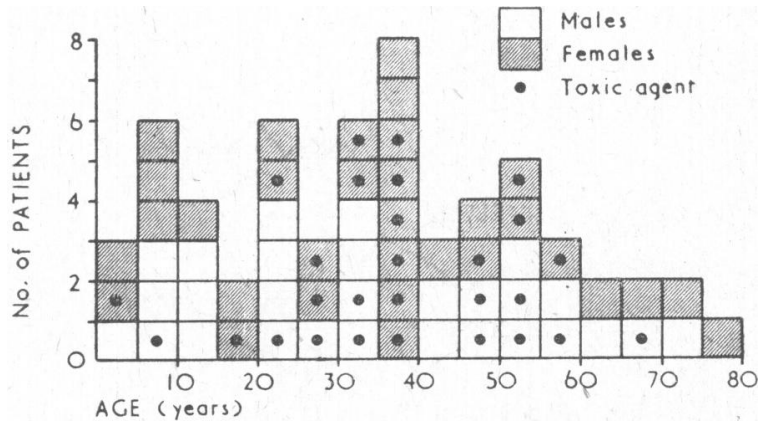

FIG. 1.-Age and sex distribution and incidence of "toxic" agents in 60 patients with acquired aplastic anaemia.

TABle I.-Drugs and Chemicals Associated with Aplastic Anaemia in \begin{tabular}{lll|c|ll|c}
\multicolumn{2}{c|}{ Agent } & & $\begin{array}{c}\text { No. of } \\
\text { Cases }\end{array}$ & \multicolumn{3}{|c|}{ Agent } \\
\end{tabular}

* Recorded by the Panel on Hematology of the Registry on Adverse Reactions, A.M.A. Council on Drugs, as having been shown by direct or circumstantial evidence to be associated with the development of aplastic anaemia.
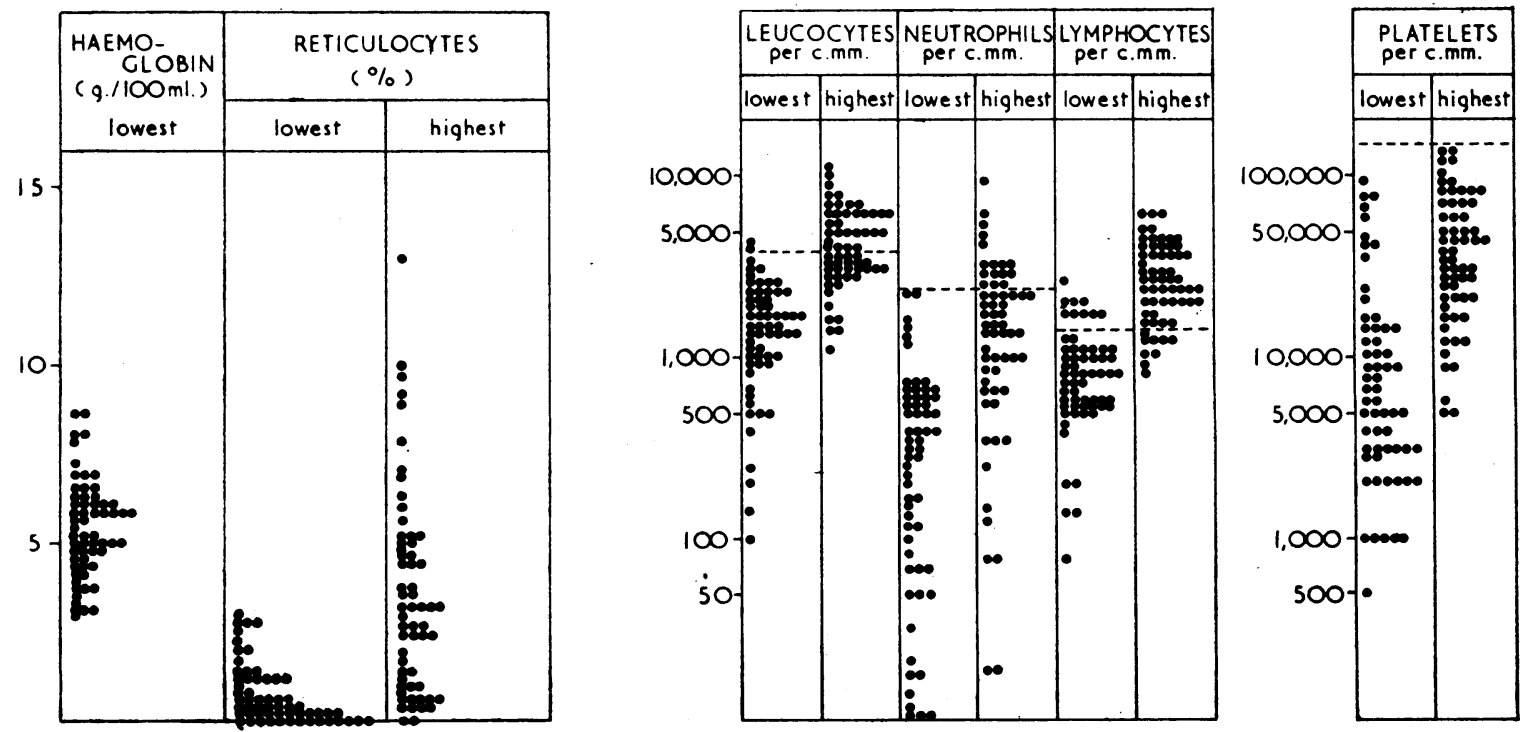

Fig. 2.-Range of haematological data in 60 patients with aplastic anaemia. The broken lines indicate the lower limit of normal. 


\section{Haematological Findings}

Blood Counts (Fig. 2).-The anaemia was usually severe, with lowest levels of haemoglobin between 3 and $8.8 \mathrm{~g} . / 100 \mathrm{ml}$. Almost all cases had an absolute reticulocytopenia at some stage, but the reticulocyte count varied and in one case was as high as $13 \%$. Fluctuations in the reticulocyte count in this patient are illustrated in Fig. 3. The neutrophil count was usually low, but in half the cases it was normal on occasions. By contrast the platelets were almost invariably lower than normal. It is of interest to note the occurrence of a lymphopenia in the majority of patients at some stage.

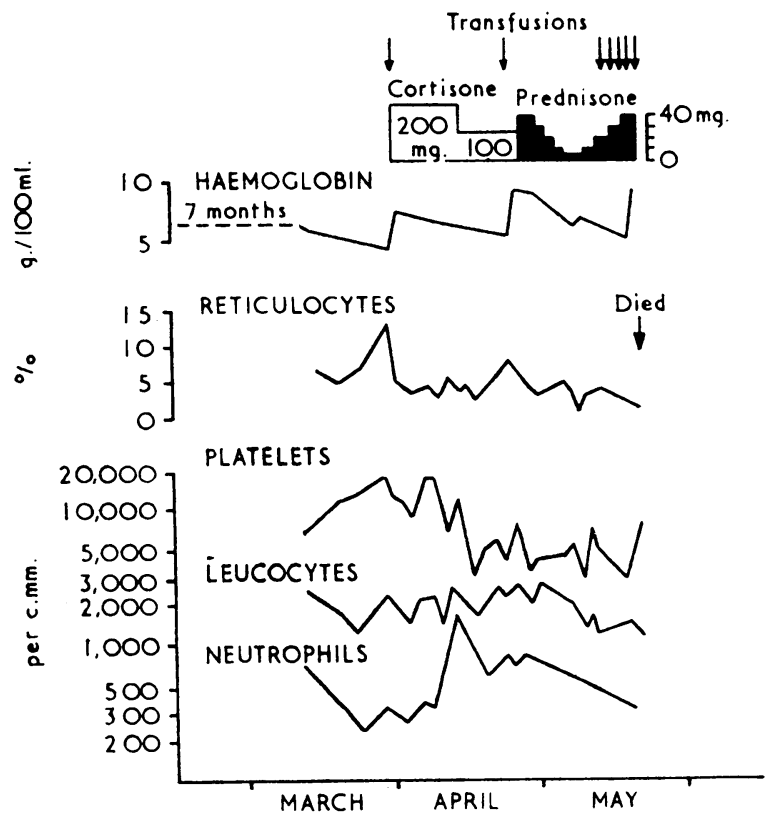

FIG. 3.-Haematological observations on a woman aged 67 with aplastic anaemia in whom there was a reticulocytosis of $13 \%$ at one stage. There was a downhill course, and the patient died ten months after onset.

Bone-marrow.-In all but two cases the diagnosis was confirmed in life by examination of the bone-marrow. In over a third (22 cases), however, a single aspiration was misleading, as normal or hypercellular material was obtained and the diagnosis could be confirmed only when the hypoplastic nature of the marrow was demonstrated either by further aspirations or by means of trephine biopsy of the iliac crest. In some cases the patchiness of cellularity was well illustrated by the presence of a focus of hypercellular marrow adjacent to an aplastic area.

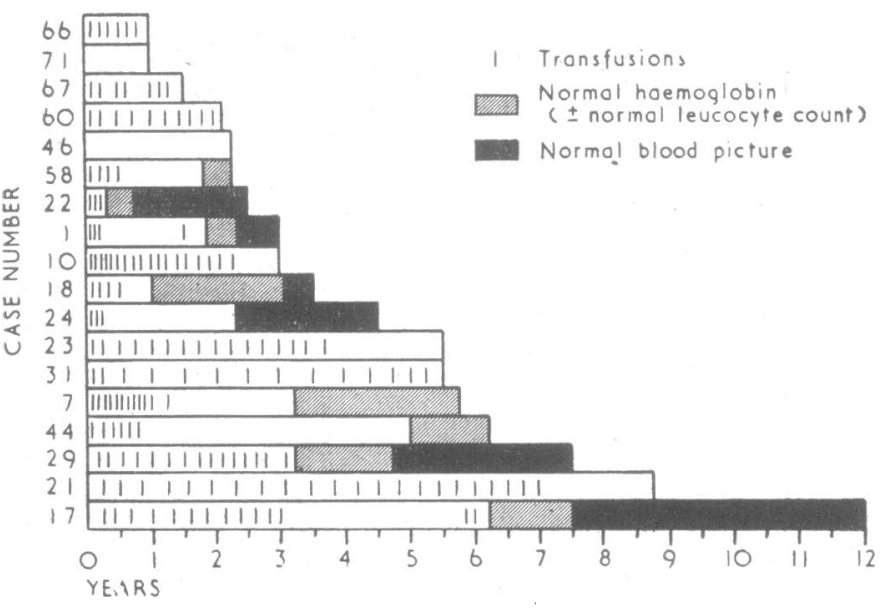

FIG. 4.-Illustration of course in 18 patients known to be alive at time of study.

\section{Course}

Patients have been followed until they have died or, if still living, for at least 12 months, and the percentage surviving has been calculated from the members still in the series at sixmonthly intervals. Within six months $20 \%$ of the patients had died and within 15 months half were dead. In some the course has been explosive, with rapid deterioration and death within weeks of onset. In others the disease has been long continued. Eighteen patients are still alive (Fig. 4). Of these, two with moderately severe anaemia have never been transfused and 12 others no longer require transfusions. Only nine are in a state of remission with normal haemoglobin with or without neutropenia. The platelets have recovered last, and in only six cases so far has there been a full remission. As a rule recovery has been very gradual, and in only one patient (Fig. 4, Case 22) has there been a relatively rapid recovery.

\section{Influence of Clinical and Haematological Data on Prediction of Prognosis}

Age and Sex.-There was no significant difference in survival between different age-groups of childhood and young adults, but prognosis was worse in patients over the age of 40 . In this group median survival was 12 months and $90 \%$ were dead within two years. Males and females were equally affected.

Aetiological Factors.-There was little difference in survival between patients in whom a toxic agent was implicated and those with no such history (Fig. 5).

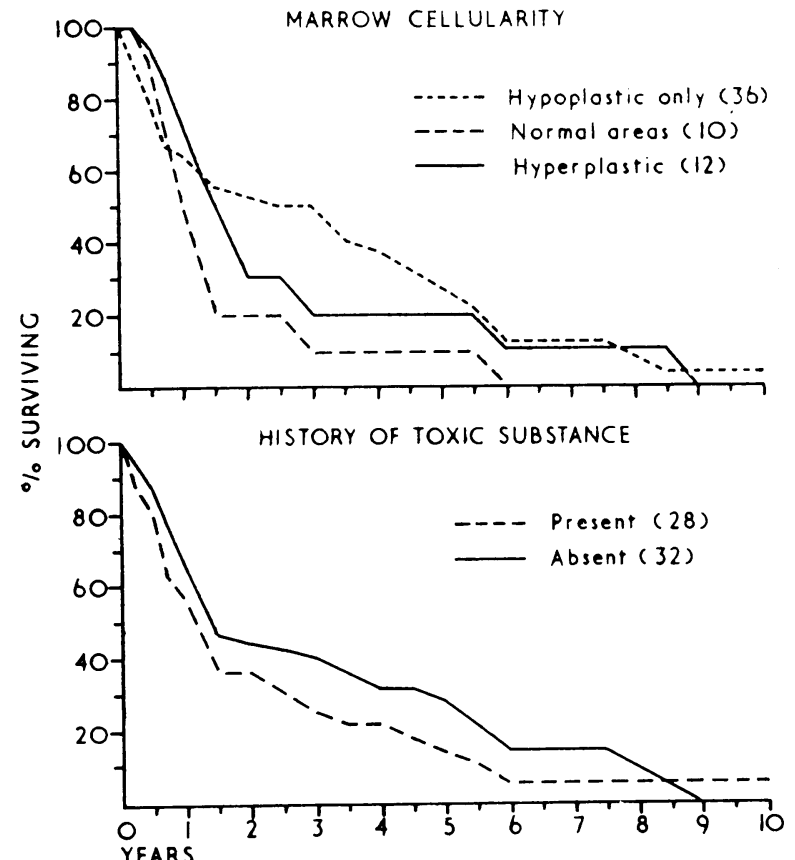

FIG. 5.-Graphs of survival of patients with aplastic anaemia, showing the influence on prognosis of variation in marrow cellularity and the difference in prognosis between "idiopathic" and " secondary" types.

Blood Counts.-To an extent prognosis seemed to be related to the degree of anaemia. Whereas some patients died within a few months irrespective of the haemoglobin level, generally patients with higher haemoglobin tended to survive longer: when haemoglobin concentration was greater than $5 \mathrm{~g} . / 100 \mathrm{ml}$. median survival was two years, compared with one year in patients with lower haemoglobin. Reticulocytosis was possibly associated with a very slightly more favourable prognosis, although there were wide fluctuations in the reticulocyte count in individual patients, and in one patient who had a relatively high reticulocyte count at one stage there was a rapid downhill course (Fig. 3). Fifteen patients had a profound neutropeniafewer than $100 /$ c.mm. - and in these patients the outlook was 
especially grave. However, in almost all cases in this group there was also severe thrombocytopenia, and on the whole neutropenia alone was not an important factor whereas the degree of thrombocytopenia was clearly significant (Fig. 6). This is borne out by the fact that in 30 patients in whom necropsies have been carried out death was due to haemorrhages in 27 , and in only three was infection thought to be significant (bronchopneumonia, two cases ; staphylococcal septicaemia, one case).

Bone-marrow.-Prognosis was not significantly improved by the presence of foci of normal or hyperplastic marrow (Fig. 5).

\section{Effects of Treatment}

The majority of the patients have been treated with combinations of steroids, testosterone, and/or anabolic hor-

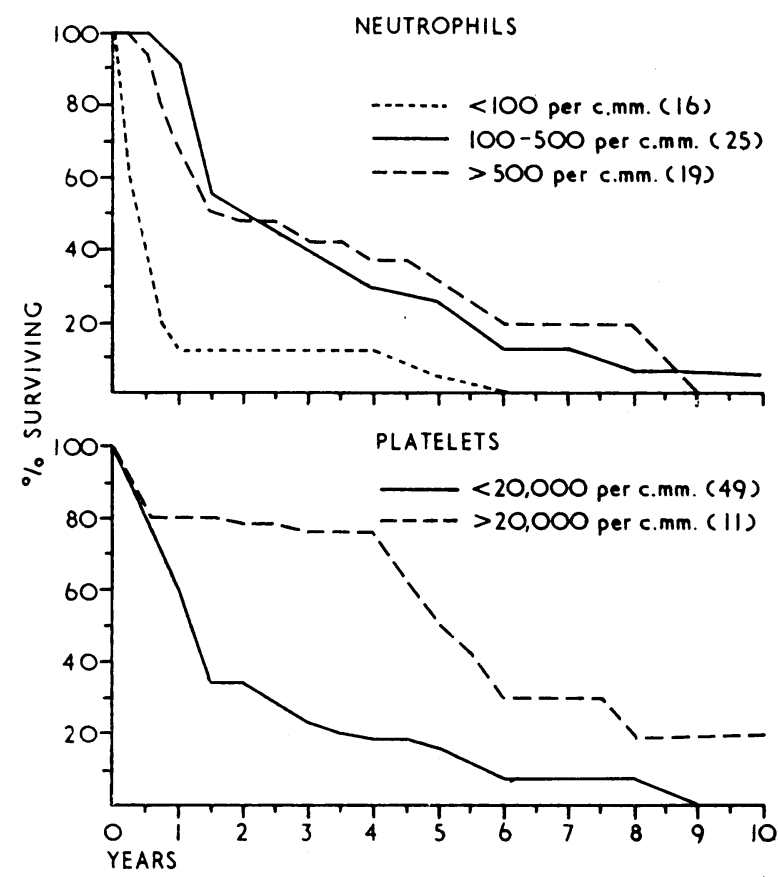

FIG. 6.-Graphs of survival of 60 patients with aplastic anaemia, showing the influence of variations in neutrophil and platelet counts on prognosis.
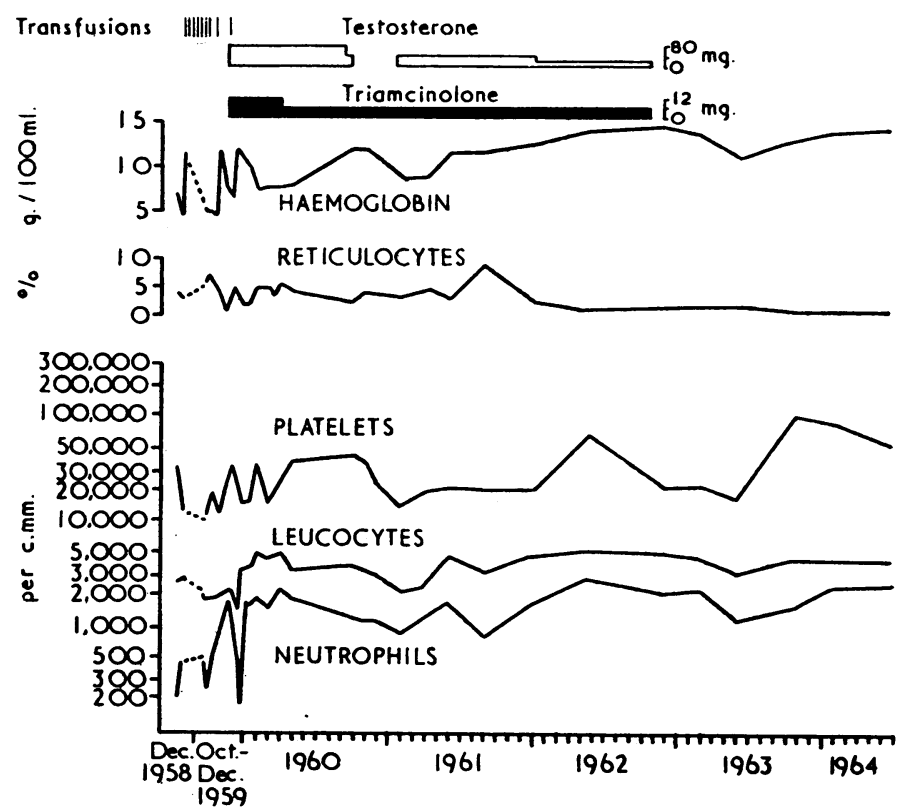

FIG. 7.- Haematological observations on a boy aged 12 with aplastic anaemia showing gradual improvement. There was a clear relation between testosterone therapy and partial remission, but the platelet count is not yet normal. mones, while all but two have been transfused from time to time. An analysis of the effects of treatment is made difficult by the fact that the most severe cases have tended to have the most intensive therapy, and more recently patients have had the advantage of better transfusion techniques, especially with regard to the use of platelets. Formerly androgens were used in low doses, but the amount of testosterone given has recently been increased to a daily dose of $2 \mathrm{mg}$. $/ \mathrm{kg}$., as testosterone propionate or an equivalent amount of a sublingual testosterone compound. In some instances there has been a definite correlation between the treatment with testosterone and improvement in the blood picture. This has been seen especially in cases occurring in childhood, near puberty (Figs. 7 and 8), but has been less apparent in adults, although temporary remissions
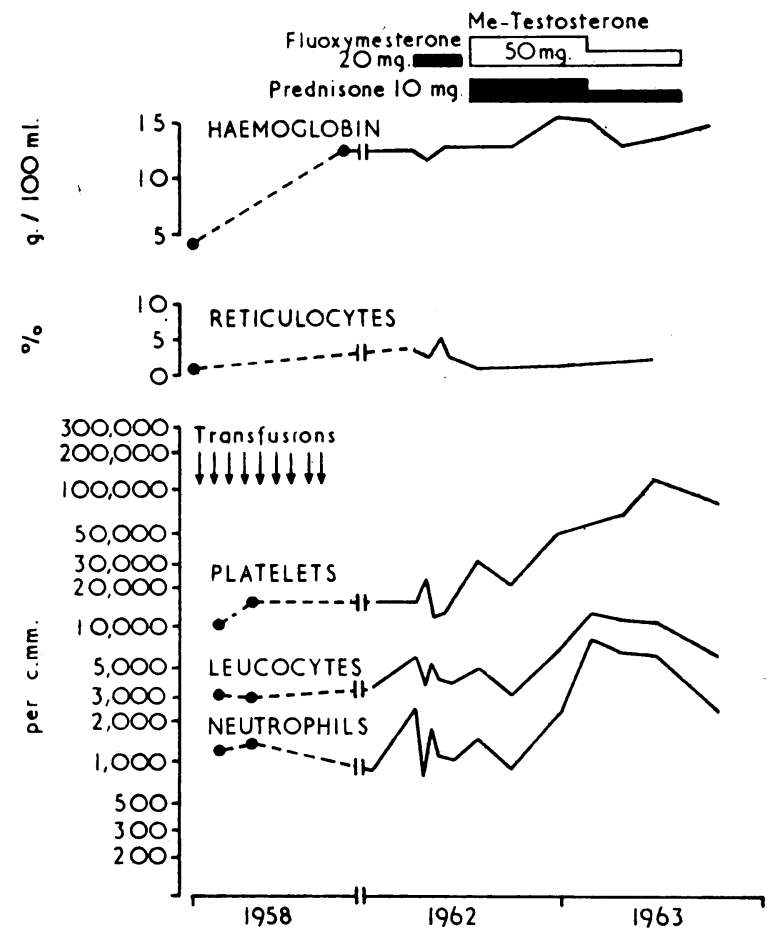

FIG. 8.-Haematological observations on a boy aged 10 with aplastic anaemia. Partial remission occurred at the time of puberty without therapy, but the platelet count remained low and there appeared to be a definite relation between the subsequent increase in the platelet count and therapy.

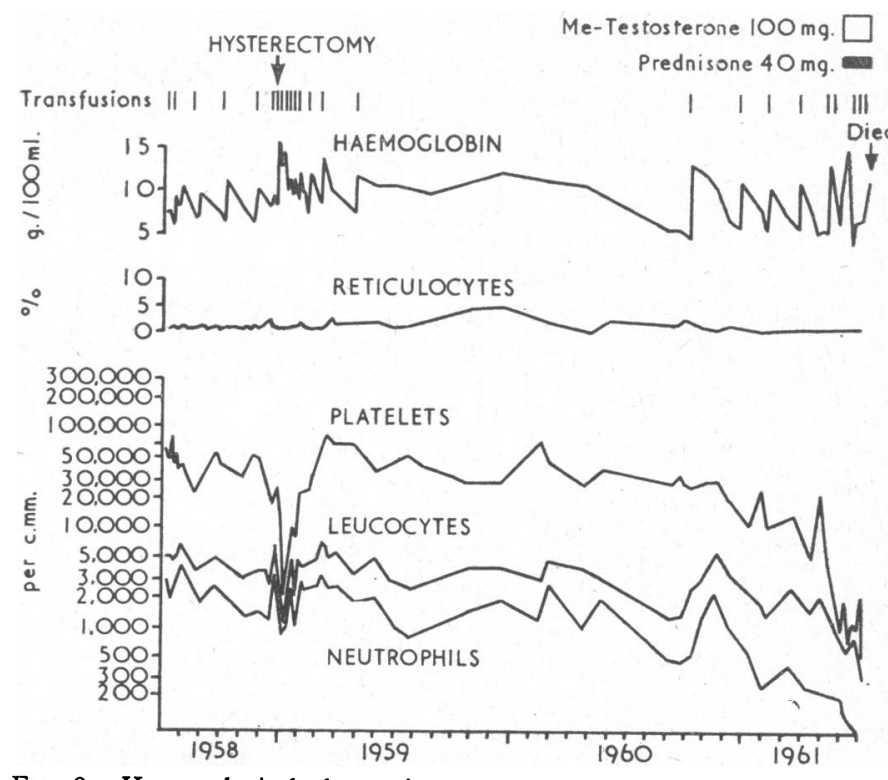

FIG. 9.- Haematological observations on a woman aged 39 with aplastic anaemia showing spontaneous remission, subsequent relapse, and ultimate death. 
have occurred in a few patients. In assessing the effect of treatment, however, it is essential to remember that this is a disease with spontaneous remissions and relapses (Fig. 9).

Any short-term benefit from treatment with androgens has not been reflected in the prognosis, and the median survival seemed little influenced by treatment with androgens and/or steroids (Table II). There is a suggestion that high doses of steroids ( $60 \mathrm{mg}$. or more of prednisone daily) may have been of less value than lower doses or than transfusions alone. Four patients underwent splenectomy. Three survived, for 8, 33, and 50 months respectively. The fourth is still alive after almost nine years and has not required transfusions for the past 21 months although she still has pancytopenia (Fig. 4, Case 21).

\begin{tabular}{|c|c|c|c|c|c|}
\hline \multirow{3}{*}{ Dead } & \multicolumn{5}{|c|}{ Months } \\
\hline & \multirow{2}{*}{$\begin{array}{l}\text { Transfusions } \\
\text { Alone }\end{array}$} & \multicolumn{2}{|c|}{ Steroids } & \multirow{2}{*}{$\begin{array}{c}\text { Steroids } \\
+ \\
\text { Androgens }\end{array}$} & \multirow{2}{*}{$\begin{array}{c}\text { Androgens } \\
\pm \\
\text { Steroids }\end{array}$} \\
\hline & & $\begin{array}{c}\text { High } \\
\text { Doses* }\end{array}$ & $\begin{array}{l}\text { Low } \\
\text { Doses }\end{array}$ & & \\
\hline $\begin{array}{l}25 \% \\
50 \% \\
75 \%\end{array}$ & $\begin{array}{r}4 \\
12 \\
70\end{array}$ & $\begin{array}{r}6 \\
12 \\
18\end{array}$ & $\begin{array}{l}12 \\
16 \\
40\end{array}$ & $\begin{array}{r}9 \\
12 \\
30\end{array}$ & $\begin{array}{l}10 \\
18 \\
48\end{array}$ \\
\hline
\end{tabular}

* $60 \mathrm{mg}$. or more of prednisone daily.

\section{Discussion}

An attempt to predict the outcome in chronic acquired aplastic anaemia and the influence of treatment is made difficult by the wide variation in intensity of the disease, by the occurrence of spontaneous remissions, and by factors other than treatment which have an effect on prognosis. Undoubtedly, aplastic anaemia is a serious disease. Mohler and Leavell (1958) analysed 50 cases, of which 37 are recorded as having had pancytopenia. They reported that 12 patients had died within a year while six lived for five years. Scott, Cartwright, and Wintrobe (1959) reported that half of a group of 39 patients lived for two and a half years and that $40 \%$ of the patients survived for four years or longer; their results show that in only four cases was the blood count normal when the patients were last seen. The prognosis appeared worse in Israëls and Wilkinson's (1961) series of 45 patients, as $45 \%$ were dead within three months. They reported that 11 of their patients remitted completely, although this included one patient with red-cell aplasia, and from their data it is seen that only two of the patients in remission have normal platelet counts-that is, $150,000 / \mathrm{c} . \mathrm{mm}$. or more-and in four the platelet counts are fewer than $100,000 / \mathrm{c} . \mathrm{mm}$.

In the present series of 60 patients there has been a $50 \%$ mortality within 15 months of onset. The outlook was especially poor in patients over the age of 40 , but the disease seemed to be relatively less serious at puberty.

Bomford and Rhoads (1941) suggested that the presence of foci of cellular or hypercellular marrow gave better hope than when the marrow aspirates were devoid of cells. But this has not been confirmed, and prognosis does not appear to be significantly improved by the presence of foci of normal or hyperplastic marrow, nor by the presence of reticulocytosis. On the whole, neutropenia appears to be of less importance than thrombocytopenia, as is indicated by the fact that patients are much more likely to die as a result of haemorrhage than from infection.

In patients who do not succumb it is a chronic disease with remissions, relapses, and occasionally complete recovery. But recovery usually takes place extremely slowly and the platelets become normal many months or even years after remission begins. Björkman (1962) reported the spontaneous recovery after 22 months of a woman who had aplastic anaemia caused by chloramphenicol. As shown in Fig. 4, there have been instances of recovery after even longer periods. In only one case in the present series has there been full remission within nine months of onset. This was a patient in whom the aplastic anaemia followed gold therapy, but as a rule there has been little or no difference in the course, or in survival, between patients in whom a toxic agent was implicated and those with no such history. An unusually rapid recovery might suggest a variant of the disease or even a different pathogenesis.

The value of steroids and androgens in the treatment of congenital aplastic anaemia is well recognized (Shahidi and Diamond, 1961; Allen and Diamond, 1961). Shahidi and Diamond also reported good response to similar treatment in cases of acquired aplastic anaemia, and Gardner and Pringle (1961) recorded the occurrence of a remission in a case of chloramphenicol-induced aplastic anaemia with methyltestosterone. In the present series there have been instances of remissions in patient receiving testosterone therapy, especially in children near puberty-for example, Fig. 7-but this treatment has usually been of less benefit in adult patients, and the ultimate prognosis and median survival seemed little influenced by treatment with moderate doses of androgens and/or steroids. It should be noted that steroids in high doses were of less value than in lower doses, but the significance of this observation is difficult to assess as the patients on the higher doses were on the whole more seriously ill.

The importance of the spleen in aplastic anaemia has not yet been elucidated. Heaton, Crosby, and Cohen (1957) reviewed the published results of splenectomy as well as their own experiences. They concluded that the operation, while unlikely to result in spectacular benefit, was not infrequently followed by modest improvement with decreased transfusion requirements. Scott et al. (1959) also reported favourably on the value of splenectomy. Lewis (1962) has shown that in aplastic anaemia there is frequently a haemolytic element, and in a third of the patients studied there was evidence that the spleen was a significant site of red-cell sequestration. It is conceivable that in these patients splenectomy would have been of some benefit in controlling at least this one aspect of the anaemia. Unfortunately the present study provides no evidence for or against this hypothesis as splenectomy has not been performed on any of the patients who showed evidence of splenic sequestration of red cells, and isotope studies were not carried out before splenectomy in the four patients who underwent the operation.

As might be expected, patients with the most severe pancytopenia run the gravest risk of early death, but, while it is not possible to predict the eventual outcome in an individual patient from the initial haematological data, it is apparent that the longer a patient survives the better is his chance of ultimate remission and perhaps cure. As indicated above, the value of androgens and steroids is still uncertain, and in the absence of any specific therapy the prime aim should be to control the blood picture. Anaemia is readily corrected and even severe neutropenia is not as a rule a significant problem, whereas death has usually been due to haemorrhage associated with severe thrombocytopenia. Thus it is of paramount importance to control haemorrhage by the use of fresh blood or platelet transfusions when necessary, especially when such haemorrhage results in a vicious circle of increasing thrombocytopenia.

Prognosis may also be affected by the onset of some other haematological disorder which may be causally related. Acute leukaemia has occurred as a terminal event in patients previously shown to have pancytopenia and marrow aplasia (Adams, 1951; Block, Jacobson, and Bethard, 1953). It is uncertain whether these represent two phases of the same illness or whether the fundamental disease is leukaemia with an unusual form of presentation. The ultimate prognosis becomes that of the leukaemia. There have been no cases with this termination in the present series.

Paroxysmal nocturnal haemoglobinuria (P.N.H.) is another disease which may occur as a complication of aplastic anaemia, possibly with a greater frequency than hitherto recognized. Dacie and Lewis (1961) recorded its occurrence in a woman 
with acquired aplastic anaemia. Since then three other adult patients apparently suffering from aplastic anaemia have developed P.N.H.: in two the P.N.H. defect became severe and dominated the picture, while the fourth patient had a mild P.N.H. defect and died while the aplastic phase was still dominant. These cases have not been included in the series analysed above, although in their initial presentation they were indistinguishable from acquired aplastic anaemia. They are recorded here to draw attention to the fact that the possibility of the development of P.N.H. should perhaps be considered when the prognosis in aplastic anaemia is assessed.

\section{Summary}

In a 12-year period 60 patients suffering from chronic acquired aplastic anaemia have been investigated. In some cases the disease has run an acute course with death in weeks. Half the patients died within 15 months of onset. Eighteen are still alive but only six are in full remission, while another three are in partial remission with normal haemoglobin, with or without neutropenia, but with persistence of thrombocytopenia. Invariably platelets have been the last component to return to normal, usually after a prolonged period.

Both sexes were equally affected, but the outlook may be more serious in patients over the age of 40 ; it was especially grave in a group of 16 patients who had profound neutropenia (fewer than 100/c.mm.) and severe thrombocytopenia (fewer than $20,000 /$ c.mm.), but on the whole neutropenia did not materially affect prognosis to the same extent as did thrombo-

\title{
Value of Detection of Formiminoglutamic Acid in Urine for the Diagnosis of Malabsorption States
}

\author{
DAVID P. ROSE,* M.D.
}

Increased amounts of formiminoglutamic acid (Figlu), an intermediate metabolite in the degradative conversion of histidine to glutamic acid (see Fig.), may appear in the urine of patients with folic-acid deficiency, vitamin- $\mathrm{B}_{12}$ deficiency, and liver disease. Figlu is converted to glutamic acid by transfer of its formimino group to tetrahydropteroylglutamic acid. Folic-acid deficiency results in an accumulation of Figlu due to a lack of tetrahydropteroylglutamic acid, and consequently increased amounts of Figlu appear in the urine (Tabor and Wyngarden, 1958). The increased urinary excretion of Figlu in vitamin- $B_{12}$ deficiency also probably results from a reduction in available tetrahydropteroylglutamic acid (Herbert and Zalusky, 1962). In liver disease the enzymes concerned in the metabolic pathway of histidine degradation may be impaired, and reduced activity of one of these enzymes, Figlu transferase, may be responsible for the increased excretion of Figlu in liver disease without folic-acid deficiency (Merritt, Rucknagel, Silverman, and Gardiner, 1962).

Knowles (1962) has studied the urinary excretion of Figlu, using it as an index of folic-acid deficiency, in steatorrhoea and concluded that this provides a satisfactory screening test for idiopathic steatorrhoea.

In the present study the clinical value of determining the urinary excretion of Figlu has been assessed in malabsorption

* Department of Chemical Pathology, United Sheffield Hospitals. cytopenia; death was usually due to haemorrhage rather than infection. In 22 cases bone-marrow aspiration showed normal or hyperplastic foci, but prognosis was little affected by this.

Evaluation of treatment is difficult, as spontaneous remissions may occur, but testosterone and corticosteroids in moderate doses can induce remissions in children near puberty. In adults prognosis and median survival seemed little influenced. Fresh blood or platelet transfusions were valuable during haemorrhagic episodes. Splenectomy was carried out in four patients with equivocal results.

I wish to thank Professor J. V. Dacie for his guidance and encouragement, and the physicians of Hammersmith Hospital and elsewhere who referred patients to Professor Dacie's department.

\section{REFERENCES}

Adams, E. B. (1951). Lancet, 1, 657.

Allen, D. M., and Diamond, L. K. (1961). Amer. F. Dis. Child., 102, 416.

Börkman, S. E. (1962). Acta haemat. (Basel), 27, 124.

Block, M., Jacobson, L. O., and Bethard, W. F. (1953). f. Amer. med. Ass., 152, 1018

Bomford, R. R., and Rhoads, C. P. (1941). Quart. F. Med., 10, 235.

Dacie, J. V., and Lewis, S. M. (1961). Brit F. Haemat., 7, 442.

Gardner, F. H., and Pringle, J. C., jun. (1961). Arch. intern. Med., 107,

846.
Heaton, L. D., Crosby, W. H., and Cohen, A. (1957). Ann. Surg., 146, 637.

Irsaëls, M. C. G., and Wilkinson, J. F. (1961). Lancet, 1, 63.

Lewis, S. M. (1962). Brit. F. Haemat., 8, 322.

Mohler, D. N., and Leavell, B. S. (1958). Ann. intern. Med., 49, 326.

Scott, J. L., Cartwright, G. E., and Wintrobe, M. M. (1959). Medicine (Baltimore), 38, 119.

Shahidi, N. T., and Diamond, L. K. (1961). New Engl. F. Med., 264, 953. states due to a variety of causes. Particular attention has been paid to the likelihood of causes of abnormal excretions other than folic-acid malabsorption resulting in an erroneous diagnosis of small-bowel disease.
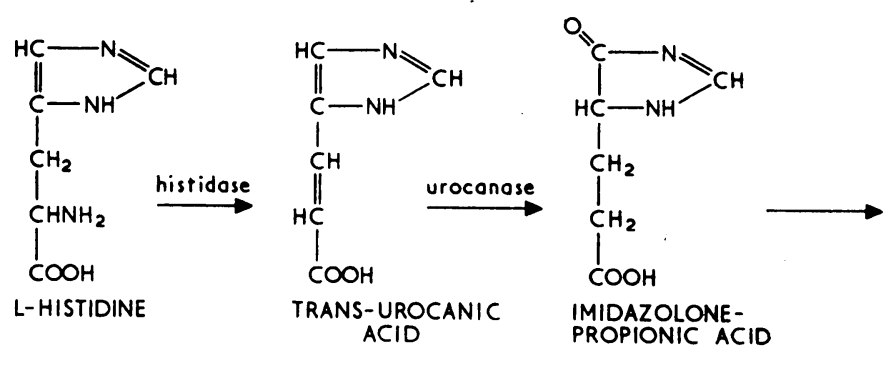

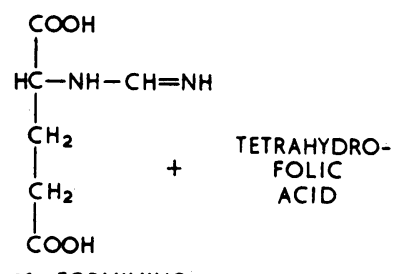

$\propto$ - FORMIMINO-

GLUTAMIC ACID
The metabolic pathway by which histidine is converted to glutamic acid. 